\title{
Pós-graduação no exterior: caminhos e oportunidades com base na experiência de dois fisioterapeutas
}

Inae Caroline Gadotti

(Ft, MSc Ft, Doutoranda)

University of Alberta, Faculty of

Rehabilitation Medicine, 3-48 Corbett Hall,

Edmonton, Alberta, Canada T6G 2G4

E-mail: igadotti@ualberta.ca

http://myprofile.cos.com/igadotti

http://www.uofaweb.ualberta.ca/rehabmed

Bolsista CIHR (Canadá)

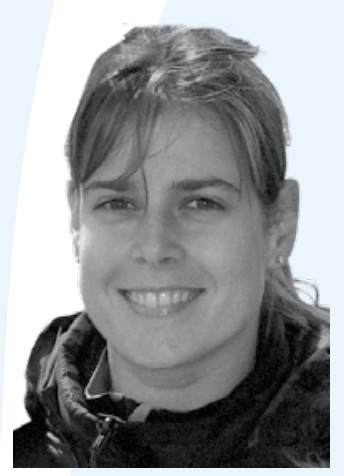

Edgar Ramos Vieira

(Ft, MSc, PhD)

Programa de Mestrado em Ciências da

Reabilitação;

Universidade Nove de Julho (Uninove)

Av. Francisco Matarazzo, 612, Água Branca,

05001-100 - São Paulo, SP - Brasil

Telefone: (11) 36659325 Fax: (11) 36659301

E-mail: evieira@uninove.br

http://myprofile.cos.com/evieira

Ex-bolsista CAPES (doutorado no exterior) 
Muitos colegas nos escrevem perguntando sobre oportunidades e o processo para fazer pós-graduação no exterior. Esta entrevista apresenta as informações que acreditamos sejam relevantes para os colegas que têm interesse nessa possibilidade. Gostaríamos de esclarecer que as informações contidas neste artigo referem-se apenas às nossas experiências e conhecimento limitado sobre pós-graduação no exterior. Temos certeza de que existem muitas outras oportunidades e diferentes procedimentos os quais não conhecemos. Contudo, acreditamos que, com a leitura deste artigo, possamos contribuir com os profissionais da área da saúde que almejam estudar no exterior.

Para contextualizar o leitor, contamos um pouco sobre nossa trajetória profissional. Graduamo-nos em fisioterapia (1996-1999) pela Universidade Metodista de Piracicaba (Unimep). Durante a graduação, fizemos estágios curriculares e extracurriculares, além de monitorias e projetos de iniciação científica. Participamos também de projetos de pesquisa durante a graduação e de apresentações de diferentes trabalhos em congressos. Com base nas experiências durante os projetos de iniciação científica e durante a monografia de conclusão de curso, decidimos fazer mestrado em Fisioterapia na Universidade Federal de São Carlos (UFSCar). Durante o mestrado, tivemos contato com docentes altamente qualificados, com experiência no exterior e, como resultado dessa experiência, decidimos fazer doutorado em outro país, o que nos proporcionaria a oportunidade de conhecer outra cultura, ter contato com pesquisadores renomados internacionalmente, estudar em uma universidade de grande prestígio e aprender bem outra língua.

\section{PRIMEIROS PASSOS E BARREIRAS}

Os primeiros passos envolvidos na busca de uma pós-graduação no exterior incluem a procura por informações a respeito de universidades, pesquisadores, agências de fomento à pesquisa internacionais e nacionais, bolsas de estudo, visto, requisitos dos programas de pósgraduação, certificados de proficiência na língua do país, moradia, custo de vida, seguro saúde, possíveis barreiras culturais, qualidade de vida em diferentes países, clima (obs.: onde moramos chega a fazer $-40^{\circ} \mathrm{C}$ ), possível discriminação, formas de lidar com a saudade e a distância da família e de amigos. Enfim, uma infinidade de fatores importantes para a concretização do plano. Nesta fase, as barreiras e dificuldades se tornam mais evidentes. Embora não nos surpreenda, achamos interessante que muitos dos colegas que entram em contato conosco, nunca mais nos escrevam quando informamos o que é necessário e os procedimentos envolvidos para fazer pós-graduação no exterior.

\section{ESCOLHA DA UNIVERSIDADE, DO ORIENTADOR E CONTATO INICIAL}

A escolha da universidade, programa e orientador da pós-graduação no exterior são cruciais. Deve-se considerar a excelência da universidade pretendida, as condições oferecidas pelo programa e a produção, disponibilidade e afinidade com o orientador. Procure saber quem são os pesquisadores renomados na área de interesse. Os autores dos artigos que lhe interessam podem ser uma boa opção. Tenha uma idéia concreta (projeto) do que você gostaria de fazer no doutorado. $\mathrm{O}$ projeto provavelmente mudará um pouco, ou muito, como conseqüência da interação com o(a) orientador(a), mas uma idéia inicial é fundamental para iniciar o contato e expor seus interesses de pesquisa.

É muito importante basear a escolha não apenas nos interesses de pesquisa em comum, mas também com base no relacionamento interpessoal com o(a) orientador(a). Embora seja muito difícil saber como será essa relação, procure conhecer um pouco sobre quem poderá orientá-lo. Leia o currículo do possível orientador(a), sua história, sua origem etc. Converse com outros orientandos e procure saber como se processa o relacionamento no diaa-dia. A disponibilidade do(a) orientador(a) 
para conversar sobre a pesquisa será fundamental a seu desenvolvimento, principalmente no início do programa de estudos.

Caso queira estudar em uma universidade específica, um bom começo é pesquisar o site do departamento e o programa pretendido. Leia sobre os interesses de pesquisa dos diferentes professores do programa e seus currículos para decidir quem potencialmente seria um(a) orientador(a) ideal, considerando seus objetivos. Outros alunos do programa de pós-graduação passaram por experiências similares, conhecem todo o procedimento, os diferentes professores etc.; por isso, são ótima fonte de informação.

Contamos com diferentes formas de incentivo acadêmico. Edgar, por exemplo, obteve o auxílio de sua orientadora de mestrado que tinha feito o pós-doutorado no laboratório onde ele está atualmente. A orientadora iniciou o contato de Edgar com seu atual orientador. Após alguns meses de troca de e-mails com o orientador no exterior, os quais foram escritos com a ajuda de uma professora de inglês, o futuro orientador informou-lhe que, caso fosse aceito pelo programa, ele o orientaria, sugerindo-lhe que entrasse em contato com a secretaria do programa, a qual o informaria sobre os procedimentos para a candidatura. Já os colegas que não tenham ninguém para facilitar esse processo inicial podem fazer o contato diretamente. É provável que alguns pesquisadores não respondam aos e-mails, mas com sorte, um pouco de pesquisa e muita insistência, alguns o farão. Esta é a experiência de outros colegas brasileiros aqui e em outras universidades no exterior. O contato inicial não precisa ser necessariamente com o orientador em si, mas pode ser feito com o coordenador do programa que, possivelmente, o encaminhará para o pesquisador em sua área de interesse.

O meu caso foi um pouco diferente. Durante o mestrado, fui para o Canadá fazer um curso de inglês e avaliar oportunidades para fazer doutorado na Universidade de Alberta. Entrei em contato com o orientador de interes- se. Após duas reuniões, ele me informou que me orientaria caso fosse aceita pelo programa.

Gostaríamos de ressaltar que os diferentes caminhos seguidos por nós apresentam vantagens e desvantagens. Edgar teve o contato inicial facilitado por uma pessoa que conhecia o orientador e o programa. Ele não foi ao exterior e, portanto, não precisou arcar com as despesas envolvidas. Por outro lado, não teve a oportunidade de conhecer o orientador pessoalmente nem a universidade ou a cidade. Eu, entretanto, pude conversar pessoalmente com meu orientador antes de iniciar o doutorado. Também tive a oportunidade de conhecer a universidade, o lugar onde viveria durante o doutorado e pude aprimorar o inglês, o que facilitou o processo inicial de transição e adaptação, mas precisei investir nesse processo.

\section{CANDIDATURA AO PROGRAMA DE PÓS-GRADUAÇÃO}

Cada programa possui suas próprias regras. O website do programa apresentará muitas informações, e a secretaria ou secretário(a) do programa é provavelmente a pessoa indicada para entrar em contato. Ela normalmente enviará informações adicionais e os formulários para candidatura (caso não estejam disponíveis online). Como exemplo, citamos os procedimentos e documentos solicitados pelo programa onde estamos cursando o doutorado. Para a candidatura eles pediram:

- Formulários de candidatura ao doutorado;

- Curriculum vitae;

- Históricos escolares da graduação e mestrado (tradução juramentada);

- Diplomas de graduação e mestrado (tradução juramentada);

- Três cartas de referência;

- Resumo do projeto de pesquisa;

- Certificado de proficiência em inglês (Test of English as a Foreign Language - TOEFL); 
Um exame de avaliação de pensamento crítico, escrita analítica e aptidões verbal e quantitativa (Graduate Record Examination - GRE).

\section{BOLSAS}

As agências de fomento brasileiras não financiam mestrado no exterior. As que fornecem bolsa de doutorado completo são: Coordenação de Aperfeiçoamento de Pessoal de Nível Superior - CAPES (http://www.capes.gov. $\mathrm{br} / \mathrm{capes} /$ portal/conteudo/10/Modalidades_ Bolsas_Exterior.htm) e Conselho Nacional de Desenvolvimento Científico e Tecnológico - CNPq (http://www.cnpq.br/bolsas_auxilios/ normas/is0405.htm). O número de bolsas para nossa área é muito limitado. Entre os fatores de grande peso na avaliação estão o currículo do candidato e do orientador no exterior, com ênfase nas publicações. Outros fatores são o projeto de pesquisa pretendido, as cartas de recomendação e o histórico do aluno. As agências requerem um certificado de proficiência na língua do país de destino, carta de aceite do orientador e carta de aceite do programa de doutorado no exterior. A CAPES solicita:

- Formulário de inscrição;

- Plano de estudos em português;

- Curriculum vitae preenchido na plataforma Lattes;

- Diplomas ou comprovantes de conclusão de graduação e de pós-graduação;

- Históricos escolares de graduação e de pósgraduação já concluída ou em andamento;

- Três cartas de recomendação de professores/pesquisadores;

- Curriculum vitae resumido do orientador;

- Correspondências trocadas com o orientador, manifestando interesse no projeto proposto, informando a área de conhecimento e a duração do projeto.

O processo da CAPES é dividido nas fases de análise documental, análise de mérito, entrevista e seleção final.
O CNPq solicita os seguintes documentos:

- Formulário de inscrição;

- Plano de estudos em português;

- Curriculum vitae preenchido na plataforma Lattes;

- Diplomas ou comprovantes de conclusão de graduação e de pós-graduação;

- Históricos escolares de graduação e de pósgraduação já concluída ou em andamento;

- Duas cartas de recomendação de professores/pesquisadores;

- Curriculum vitae do orientador;

- Evidências de contato com a instituição no exterior e com o futuro orientador;

- Para candidatos com vínculo empregatício: carta da instituição de vínculo, explicitando a importância da proposta e as condições de aproveitamento do candidato;

- Para candidatos sem vínculo: declaração de universidades, institutos de pesquisa científica e tecnológica, empresas públicas de pesquisa e desenvolvimento, ou centros de pesquisa e desenvolvimento de empresas privadas, manifestando interesse no programa proposto e no trabalho do candidato após seu retorno.

Informações detalhadas sobre os procedimentos e documentos exigidos pelas agências de fomento brasileiras estão disponíveis nos websites fornecidos. Contudo, vale ressaltar que essas agências exigem o retorno do bolsista ao Brasil, após a conclusão da pós-graduação.

Além das bolsas de doutorado integral, as agências CAPES, CNPq e as Fundações de Amparo à Pesquisa dos Estados (FAPs) fornecem bolsas de estágio doutoral no exterior ou doutorado "sanduíche", além de bolsas de pós-doutorado. Informações detalhadas podem ser obtidas nos sites das agências. Adicionalmente, o pretendente deve procurar informações sobre bolsas oferecidas pelo programa de interesse, por agências de financiamento do país e por agências de financiamento internacionais, tais como as bolsas do Programa Internacional de Bolsas de Pós-Graduação da Fundação Ford (www.programabolsa.org.br). Os candidatos com 
interesse em fazer pós-graduação no Canadá podem candidatar-se às bolsas dos Institutos Canadenses de Pesquisa em Saúde (CIHR - http://www.cihrirsc.gc.ca/e/27197.html) ou a bolsas específicas da província de destino. Um exemplo para o último caso são as bolsas da Fundação para Pesquisas Médicas de Alberta (AHFMR - http://www.ahfmr. ab.ca/grants/individual.php). Existem também bolsas oferecidas pelas universidades no exterior. Por exemplo, a Faculdade de Pós-Graduação e Pesquisa (FGSR) da Universidade de Alberta (Canadá) oferece bolsas de diferentes modalidades (http://gradfile.fgsro.ualberta.ca/awardsfunding/scholarships/ index.htm), e o Programa Alban, da Universidade Fernando Pessoa (Portugal), oferece bolsas de pósgraduação (www.ufp.pt).

\section{VISTOS}

Os procedimentos para obtenção de visto variam de país para país. O consulado do país de destino fornece as informações necessárias. Em geral, para emissão de visto de entrada e autorização de estudo e permanência no país por tempo pré-estabelecido, requer o passaporte, os documentos pessoais, uma carta de aceite do programa de pós-graduação e um comprovante de renda para se manter no país de destino durante o período (comprovante de aprovação da bolsa que inclua os valores concedidos, por exemplo). Informações sobre permissão para estudos no Canadá podem ser obtidas no site: http://www.cic.gc.ca/english/study/applyhow.html. Para estudos nos E.U.A, as informações estão disponíveis no site: http://www.unitedstatesvisas.gov/studying.html.

\section{DIFICULDADES}

As dificuldades são aquelas relacionadas ao processo de candidatura e bolsas e as relacionadas à adaptação e à língua. Os processos de candidatura ao programa e bolsas são similares. Muitos dos documentos que precisam ser enviados para o programa também devem ser mandados para as agências de fomento. No caso de agências brasileiras, os documentos devem estar escritos em português. Portanto, em muitos casos, é necessário ter os documentos nas duas línguas (português e língua do país de destino). Os programas de pós-graduação requerem que os históricos e diplomas sejam traduzidos (tradução juramentada). Essas traduções não são baratas.

Um dos requisitos importantes na seleção dos candidatos para os programas e para bolsas são as publicações em periódicos científicos. Portanto, invista em publicar, pois isso será fundamental para seu futuro e sucesso na pós-graduação e vida acadêmica.

Os exames de proficiência na língua do país de destino não são fáceis, esteja preparado e estude com muita antecedência. Prepare-se, faça muitos exames simulados antes de ir para a prova. Os exames têm uma estrutura específica. Mesmo que você saiba muito bem a língua do país de destino, não significa que você conseguirá obter uma boa nota no exame. O contrário também é verdadeiro, ou seja, o fato de você ter obtido uma boa nota no exame de proficiência não quer dizer que você tem o domínio da língua. Procure ver televisão e assistir a filmes na língua do país de destino. Evite ler as legendas. Converse com outros colegas que sabem um pouco da língua; enfim, pratique muito. Os primeiros meses no exterior não são fáceis, mas caso você esteja mais confortável com a língua, esse processo será muito mais tranqüilo. Lembre-se de que, logo após chegar ao exterior, é provável que suas aulas tenham início imediato e, acredite, não haverá legenda (por mais que quisermos). Os cursos não são fáceis, e o fato de serem ministrados em outra língua faz que o desafio seja maior.

Para aqueles que pretendem fazer pósgraduação no Canadá ou nos Estados Unidos, a maioria das universidades nesses países requer o Graduate Record Examination (GRE). O GRE é um exame de avaliação de pensamento crítico, escrita analítica e aptidões verbal e quantitativa. $\mathrm{O}$ teste envolve conhecimentos adquiridos ao longo da vida escolar e assemelha-se a um 
vestibular com características de um teste de quociente de inteligência (QI). Pratique muito e prepare-se para estudar um pouco as coisas do colegial como álgebra e trigonometria.

A distância e a saudade são outras dificuldades. Os primeiros quatro meses parecem ser os mais difíceis. Procure fazer amigos e participar de atividades sociais. Normalmente, as universidades possuem um centro para estudantes internacionais que organiza eventos de recepção e orientação de alunos de outros países. Busque saber qual a forma mais barata de se comunicar com seus familiares. Cheque o valor das ligações para o Brasil e veja se existem cartões telefônicos com bons preços, para não ter uma grande surpresa quando sua primeira conta de telefone chegar (falamos por experiência própria). Treine os familiares e amigos que não gostam muito de computador a usar o 'ICQ', 'messenger' ou 'skype'.

\section{BENEFÍCIOS}

Os benefícios de fazer pós-graduação no exterior podem ser agrupados em pessoais e profissionais. Entre os benefícios pessoais ressaltamos a ampliação da perspectiva sobre o mundo e as pessoas. É muito bom ter a experiência de viver em outra cultura com diferentes valores. Esse processo resulta num crescimento pessoal e amadurecimento. Uma das grandes vantagens é a oportunidade de conhecer diferentes lugares e pessoas. O Canadá, por exemplo, possui uma taxa de imigração muito mais alta do que o Brasil e, por isso, conhecemos pessoas de várias nacionalidades.

Ao fazer pós-graduação em uma instituição reconhecida internacionalmente e com um orientador renomado, você terá o acesso facilitado a outros pesquisadores importantes e participará, mais freqüentemente, de eventos de prestígio internacional. É possível que 'outras portas se abram' com base nessa experiência. Contudo, é importante não nos esquecermos de nossas raízes e da contribuição que poderemos dar ao Brasil quando de nosso retorno.

\section{CONCLUSÃO}

Fazer pós-graduação no exterior é o sonho de muitos fisioterapeutas brasileiros. No entanto, o processo não é fácil e as dificuldades são muitas. Ao deparem com elas, muitos desistem. Apesar dos obstáculos, é possível fazer pós-graduação no exterior, até mesmo com financiamento nacional ou internacional. Não é fácil nem simples, mas é possível, e acreditamos que valha muito a pena. Não desanime diante das dificuldades, pois são pequenas quando comparadas com o aprendizado profissional e pessoal que se ganha. Boa sorte aos colegas que pretendem seguir o mesmo caminho! 